\title{
Modelo multivariante para la explicación de las deportaciones de migrantes desde Estados Unidos a México entre 1995 y 2016
}

\author{
Multivariante model to explain the deportations of migrants \\ from the United States to Mexico between 1995 and 2016
}

\section{Rodolfo Cruz-Piñeiro y Juan Gabino González-Becerril}

\author{
El Colegio de la Frontera Norte, México \\ Centro de Investigación y Estudios Avanzados de la Población \\ de la Universidad Autónoma del Estado de México, México
}

\section{Resumen}

El objetivo de este artículo es analizar la relación entre las deportaciones de los migrantes mexicanos desde Estados Unidos con el comportamiento de la economía estadunidense, el desempleo en ese país y con la política migratoria que incide en las deportaciones "masivas". Para probar dicha relación usamos la información del ICE, del Banco Mundial y la del Buró de Trabajo de Estados Unidos para con ello correr una regresión múltiple que confirme la relación teórica como de la empírica de las deportaciones y las variables macroeconómicas incluidas en este trabajo. De entrada se probó que la evolución de la economía y el desempleo estadunidense guardan una relación directa con las deportaciones desde dicho país. Con base en ello es que se toman las decisiones en materia de políticas migratorias que se implementan para lograr tal fin.

Palabras clave: Deportación, economía, desempleo y política migratoria.

Abstract

The objective of this article is to analyze the relationship between the deportations of Mexican migrants from the United States with the behavior of the US economy, unemployment in that country and the immigration policy that affects "massive" deportations. To prove this relationship, we used the information from the ICE, the World Bank and the Labor Bureau of the United States to run a multiple regression with the theoretical and empirical relationship of the deportations and the macroeconomic variables included in this work. From the outset it was proved that the evolution of the economy and US unemployment are directly related to deportations from that country. Based on this, decisions are made regarding migration policies that are implemented to achieve this goal.

Key words: Deportation, economy, unemployment and migration policy. 


\section{INTRODUCCIÓN}

Me es grato escribir a Usted/Y decirle en la presente/ Que aunque yo me quede ausente/

Por estos Estados Unidos/ Siempre seremos amigos.

Y nunca lo olvidaremos/ Algún día allá nos veremos/ Por aquellos territorios/

Estos interrogatorios/ Los anticipo hoy.

Porque si algún día me voy/ A refugiar con ustedes/ Espero que sus mercedes/

Reciban a un peregrino/ Que es de su mismo destino.

Corrido de la colonia, Acámbaro, Sixto Negrete

(Gamio, Manuel, s/f)

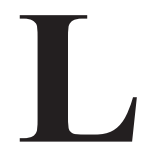

os estudios acerca de la migración internacional entre México y Estados Unidos han cambiado con el tiempo, así como sus intertaciones en el contexto del cambio de administración reciente en Estados Unidos. Algunos autores manifiestan su preocupación por la dramática desintegración ${ }^{1}$ del sistema migratorio en Estados Unidos, debido a la creciente deportación de los inmigrantes ilegales o legales (los que entran en las categorías de los indeseables), esto dio inicio a la preocupación desde principios del presente siglo al imponerse leyes migratorias cada vez más restrictivas (Tuirán y Ávila, 2010).

Sin embargo, la desintegración o separación entre inmigrantes deportados y sus familiares tienen una larga historia, la cual ha variado en el tiempo, por ejemplo, en México, a inicios del siglo XX la preocupación se centraba en la crisis económica de 1929. A dicho periodo se le conoció como la era del enganche, ${ }^{2}$ en cambio, entre 1929 y 1941, por su magnitud, se le nombró como la era de las deportaciones.

\footnotetext{
${ }^{1}$ La definición es el inverso de la integración y la definición operativa sobre los migrantes deportados incluye a los sujetos devueltos por la patrulla fronteriza o por las autoridades norteamericanas, los cuales son traducidos como acercamiento y/o distanciamiento (separación o fragmentación de familias) pero en este caso es el distanciamiento forzado. Es decir, la deportación es un proceso excluyente que desintegra a la concentración de inmigrantes en la sociedad estadunidense que crea tensiones, étnicas, raciales y de clase que lo convierte en huésped no invitado. Véase en Gallino (s/f). También en Verea (2003). Otros autores sostienen que los extranjeros se han vuelto sujetos en un terreno complejo de exclusiones e inclusiones, contención y acomodo, privaciones y afiliaciones. En este caso la deportación es un indicador de "desintegración" que contradice seriamente el énfasis discursivo en la diversidad y los derechos al trabajo que hacen las cortes estadunidenses o las agencias estatales. Mientras las preocupaciones por la "seguridad" conducen a medidas que constriñen el ámbito de actividad de los migrantes, al designarlos musulmanes de facto, y por lo tanto peligrosos. Véase en Soysal (s/f).

2 "El sistema de enganche consistía en dar al trabajador un adelanto de su salario en efectivo para luego comprometerlo a pagar su deuda con trabajo. Después del pago inicial, la deuda se incrementaba con los pasajes, hospedaje y alimentación, hasta que se arribaba al lugar de destino, pero las promesas de buenos salarios y condiciones laborales aceptables se esfumaban". Véase en Durand y Arias (2000).
} 
Posteriormente, el tema más socorrido en los estudios migratorios fue el análisis sobre el Programa Bracero, cuyo periodo comprende de 1942 a 1964 y muy poco se trató el tema de las deportaciones. Para los años siguientes, de 1965 a 1985, los estudios se centraron en la migración indocumentada que cubría la demanda de trabajadores de baja calificación en los distintos sectores de la economía estadunidense. En 1986 inician las investigaciones para entender el proceso de regularización a través de la Ley de Reforma y Control de la Inmigración (Immigration Reform and Control Act, IRCA) (Massey, Durand y Malone, 2009) en cambio a finales de la década de 1980 se analizaba la migración en el contexto de las crisis económicas y en la década de los noventa se destacaba el cambio de perfil de la migración en el contexto de la globalización y la apertura comercial, que algunos reconocieron como la nueva era de la migración o fase de la contradicción. En ese contexto también se analizaba la política unilateral del gobierno de Estados Unidos y en México la política de "no hacer política".

A inicios del siglo XXI se empezó a analizar la masificación de la migración y su diversificación por el origen y el destino como el cambio de los perfiles. A la vez que se trabajó sobre las políticas restrictivas iniciadas en 2001 bajo el concepto de seguridad nacional. Después, las investigaciones giraban en torno a nuevos patrones migratorios y la crisis económica de 2008, así como la migración de retorno voluntario y con poca atención sobre las deportaciones desde el vecino país del norte (Massey, Pren y Durand, 2009); sin embargo, es en este periodo donde ocurrieron las mayores deportaciones de la historia de nuestra relación con Estados Unidos. ${ }^{3}$ Por ejemplo, la administración Bush hijo deportó a 2.2 millones de inmigrantes y en la de Barack Obama alcanzó a 2.8 millones de personas. ${ }^{4}$

Hoy en día los medios de difusión en ambos países, los gobiernos de Estados Unidos y México, la academia y una gran diversidad de actores sociales escriben y opinan sobre la masificación de la deportación a raíz de que Donald Trump ganara la presidencia de Estados Unidos. El argumento de esta presidencia es deportar a la vez que estigmatizar a los inmigrantes como personas no deseables, criminales y un sinnúmero de calificativos que los margina, excluye y segrega bajo comentarios xenófobos y racistas.

El argumento económico estadunidense consiste en que los inmigrantes desplazan a los estadunidenses del lugar de trabajo, y por tanto, habrá que

\footnotetext{
${ }^{3}$ Esto ha traído consigo una reducción de los indocumentados mexicanos en Estados Unidos según el Centro de Investigación de Pew de 6.9 millones en 2007 a 5.6 millones de connacionales en 2016. Véase en http://www.pewresearch.org/fact-tank/2017/04/25/as-mexican-sharedeclined-u-s-unauthorized-immigrant-population-fell-in-2015-below-recession-level/

${ }^{4}$ Véase (ICE, $\mathrm{s} / \mathrm{f}$ ).
} 
poner orden. Aunque hay una gran cantidad de investigaciones que han demostrado lo contrario y que la razón de la pérdida de empleo obedece al incremento de la utilización de la tecnología robótica en distintas áreas de la producción en las empresas estadunidenses y que se acompaña con el argumento político de seguridad nacional para justificar la construcción del muro.

Por el lado mexicano, como siempre, la política de migración es de "no hacer política". Es decir, haciendo que apoyan a los migrantes diciendo lo siguiente "...el gobierno de México, va a actuar por todos los medios jurídicamente posibles para la defensa de los derechos humanos de los mexicanos en el exterior, particularmente en Estados Unidos". 5

Esta dimensión del sistema migratorio México-Estados Unidos pone a prueba a las instituciones gubernamentales en el sentido de crear una política para los retornados voluntarios y los deportados (pero sobre todo a la denominada presidencia de la cuarta transformación). Se requiere de políticas y programas que centren su atención en la reinserción si el migrante es nacido en México (retornado) e inserción y/o integración económica, social, política y cultural para los recién llegados a las distintas entidades y comunidades de nuestro país, ya que muchos de ellos son hijos de migrantes nacidos en Estados Unidos).

Con estos argumentos este texto se organiza de la siguiente manera: deportación (reconocida como la desintegración trasnacional del inmigrante) y ciclos económicos (expresados en el crecimiento económico que sintetiza la expansión o disminución de las fuerzas productivas, el trabajo, capital y circulación de mercancías), deportación y el desempleo (factor de la desintegración del inmigrante en el mercado laboral estadunidense), así como la dimensión de la política migratoria (en términos del trasnacionalismo expresa al Estado dominante mediante la imposición de política de migración versus Estado mexicano subordinado en el contexto de la globalización contra la desglobalización) (Méndez, 2016).

Abrimos un apartado para justificar el modelo de regresión, y posterior a ello, el análisis de resultados del modelo de regresión múltiple que busca probar la relación que guarda con la dimensión económica (enfatizando en el producto interno bruto y el desempleo) y la política migratoria. Por último enunciamos en líneas generales los comentarios.

\footnotetext{
5 Véase en "EU asegura que no habrá deportaciones masivas; SRE dice que solo recibirá a mexicanos", disponible en http://www.animalpolitico.com/2017/02/trump-mexicodeportaciones/
} 


\section{DisCUSIÓN DE LA RELACIÓN ENTRE LAS DEPORTACIONES DE MIGRANTES}

\section{Y SU RELACIÓN CON VARIABLES MACROECONÓMICAS}

El campo de estudios de la migración trasnacional tiene múltiples dimensiones y enfoques que han generado dimensiones y paradojas para su comprensión. Al igual que la emigración, las deportaciones ${ }^{6}$ tienen varias dimensiones a considerar: el contexto del crecimiento económico (ciclos económicos, el desempleo y el partido en el poder), la dimensión de la política migratoria restrictiva; la social, la cultural, ambiental y poblacional (Márquez, 2010; Hear, Bakewell y Long 2012; Massey y Pren, 2012; Massey y Pren, 2016) y que; sin embargo, sólo nos centraremos en las dos primeras.

La deportación, la dimensión económica y el partido en el poder: el componente cíclico de la economía puede modificar la importancia relativa de algunos grupos de migrantes dentro del total de entradas del extranjero en un país determinado. En definitiva, si la situación económica se deteriora en el país de destino es más probable que las salidas o sujetos de deportación aumentaría. Es decir, el ciclo tiene una importancia crucial en lo que podríamos denominar como cambios de planes de los inmigrantes residentes de manera temporal o permanente en Estados Unidos. En concreto, el ciclo negativo o una reducción del crecimiento económico incrementaría la probabilidad de la salida de los individuos que habiendo llegado a Estados Unidos con la intención de quedarse cambia porque la incertidumbre crece y se encuentran con una situación económica mucho peor de la que esperaban, y los pone en una condición de mayor vulnerabilidad (Lacuesta y Puente, 2010). La evidencia empírica sobre el tamaño de las deportaciones y la relación con variables económicas es relativamente escasa en comparación con la inmigración. Esto es debido a la falta de registros administrativos históricos en México no tanto desde Estados Unidos. Si bien, Estados Unidos suele contabilizar la población extranjera deportada que entra en el país de manera indocumentada, hay escasos estudios sobre deportaciones

\footnotetext{
${ }^{6}$ La deportación es uno de las tantas categorías sobre los migrantes retornados que se ha denominado: retorno obligado porque es un regreso involuntario. El migrante es forzado a regresar a casa (deportado) por la carencia de los documentos migratorios adecuados. $\mathrm{O}$ en su defecto es un retorno involuntario porque es un regreso obligado al país de origen. Generalmente relacionado con la política de expulsión de migrantes indocumentados. Véase en Jáuregui y Recaño (2014), "Una aproximación a las definiciones, tipologías y marcos teóricos de la migración de retorno", disponible en http://www.ub.edu/geocrit/b3w-1084.htm. En las economías capitalistas avanzadas regulan el flujo de los inmigrantes limitándolos o expulsándolos en épocas de crisis económicas. Paradójicamente, la fuerza laboral migrante es el remedio ideal para la crisis del capitalismo, en virtud de que la mano de obra migrante es muy productiva pero fácilmente excluible. Por su consumo reduce tensiones inflacionarias y amortigua la caída de la demanda en periodo de crisis económica. Véase en Verea (2003).
} 
de inmigrantes desde dicho país que relacionen los ciclos económicos con las deportaciones y la política restrictiva, esto obliga a que éste sea uno de los mitos a revisar en este trabajo.

La dimensión económica y la situación económica estadunidense está relacionada con la política porque en la democracia formal de élites sucede un predominio de poderes fácticos (el poder fáctico es el que se ejerce al margen de los cauces formales, es decir, que no coincide necesariamente con el aparato del Estado), y se sirve de su autoridad informal o su capacidad de presión para influir políticamente en el Estado, el individuo se vuelven mínimo y se destruye al sujeto social mediante la deportación (Márquez, 2010).

Esto implica, entonces, que la disminución de los derechos económicos, sociales y políticos de los migrantes sea acompañada por la estigmatización, clasificándolos como indocumentados, criminales, barbaros e indeseables.

La presidencia de Estados Unidos encabezada por Donald Trump ha arremetido contra los inmigrantes y ha declarado que ellos y sus familias "tienen que irse" del país. Asimismo, su propuesta va en el sentido de eliminar el Obamacare 7 y el DACA ${ }^{8}$ esto lo ha enfatizado en su discurso desde la toma de posesión el 20 de enero de $2017 .{ }^{9}$

Pero esto es mucho más profundo que el mito de la deportación y su relación con el crecimiento económico porque en el proceso electoral estadunidense se manejó como compromiso de política pública. Para ello existen varios modelos estadísticos que habían intentado predecir que iba a ganar Hillary Clinton en las elecciones del vecino país del norte, por ejemplo Moody's. ${ }^{10}$ Samuel Bentolila también comentó por qué las encuestas electorales se equivocan a menudo (Cuberes, 2016). También en un trabajo de Alan Blinder y Mark Watson (2014), dos economistas de la Universidad

\footnotetext{
${ }^{7}$ La Ley de Protección al Paciente y Cuidado de Salud Asequible (en inglés, Patient Protection and Affordable Care Act, abreviada PPACA), llamada Obamacare (Obamacuidados) por los medios norteamericanos y reforma sanitaria de Obama para los hispanohablantes, fue promulgada con carácter de ley por el presidente de los Estados Unidos Barack Obama el 23 de marzo de 2010. Junto con la Health Care and Education Affordability Reconciliation Act of 2010, esta ley es el resultado del programa de reforma de la salud del congreso con mayoría del Partido Demócrata y de la administración Obama. Véase en Obamacare en Español, disponible en https:// obamacare.net/obamacare-en-espanol/

${ }^{8}$ Orden ejecutiva del presidente Barack Obama para que los inmigrantes indocumentados que llegaron a Estados Unidos siendo niños (menores de 16 años) pueden solicitar la acción diferida que se conoce como DACA, por sus siglas en inglés (para no ser deportados). Sin embargo, el presidente Trump arresta en Estados Unidos a mexicano protegido por DACA, véase en http:// www.jornada.unam.mx/ultimas/2017/02/15/arresta-eu-a-mexicano-protegido-pro-daca

9 Véase en Donald Trump: “¿por qué no votaron?”, disponible en http://www.losandes.com.ar/ article/donald-trump-por-que-no-votaron

${ }^{10}$ Véase en "Moody's te dice quién va a ganar la presidencia de EU", disponible en http://www. elfinanciero.com.mx/economia/moody-s-te-dice-quien-va-a-ganar-la-presidencia-de-eu.html
} 
de Princeton, demostraron que a la economía de Estados Unidos le ha ido históricamente mejor bajo mandatos demócratas que bajo presidentes republicanos y que a menudo la evolución económica es un fuerte indicador de cuáles serán los resultados de las elecciones presidenciales y la política migratoria (Orgaz, 2016).

Los datos que utilizan en su estudio denominado Presidents and the U.S. Economy: An Econometric Exploration inicia con el segundo gobierno de Harry Truman en 1949 y terminan en el primer gobierno de Barack Obama en 2012. Sus hallazgos sostienen que la economía funcionó mejor en los años en los que un demócrata ocupó la Casa Blanca. Sin embargo, no implica que los demócratas lleven a cabo políticas más favorecedoras al crecimiento económico y la inmigración, sino a que éstos se vieron favorecidos por shocks petroleros positivos, a un mayor progreso tecnológico, sobre todo los basados en la tecnología de la información, un mejor entorno internacional, y mejores expectativas de los consumidores sobre el presente y el futuro. Pero el anterior presidente (Barack Obama) fue quien hizo una mayor deportación de migrantes (2.8 millones de personas) aunque en sus discursos políticos disfrazaba la rigidez de su política migratoria restrictiva.

La Tabla 1a y la Tabla 1 b muestran la evolución de la tasa de crecimiento del PIB en Estados Unidos durante el gobierno de cada presidente desde 1976. La mayor tasa de crecimiento ocurrió con Jimmy Carter (demócrata) y la más baja fue con Obama en 2008 (aunque esto no es el reflejo de su administración, véase Figura 1). La tasa de crecimiento promedio aparece a la derecha y la intención del voto para los candidatos/presidentes demócrata y republicano (en cual podemos apreciar que la menor intención del voto fue para George Bush en 2000). Los demócratas gobernaron cuando la economía estaba en una fase de crecimiento expansivo y una de las variables que explica este diferencial de crecimiento es el gasto del gobierno durante la guerra de Corea (1950-1953). Otras variables que parecen explicar alguna diferencia en el crecimiento económico estadunidense son los shocks de petróleo de 1973 y 1979, los de productividad y, en algún caso, el gasto en defensa, el crecimiento económico en el resto del mundo, y el optimismo de los consumidores. 


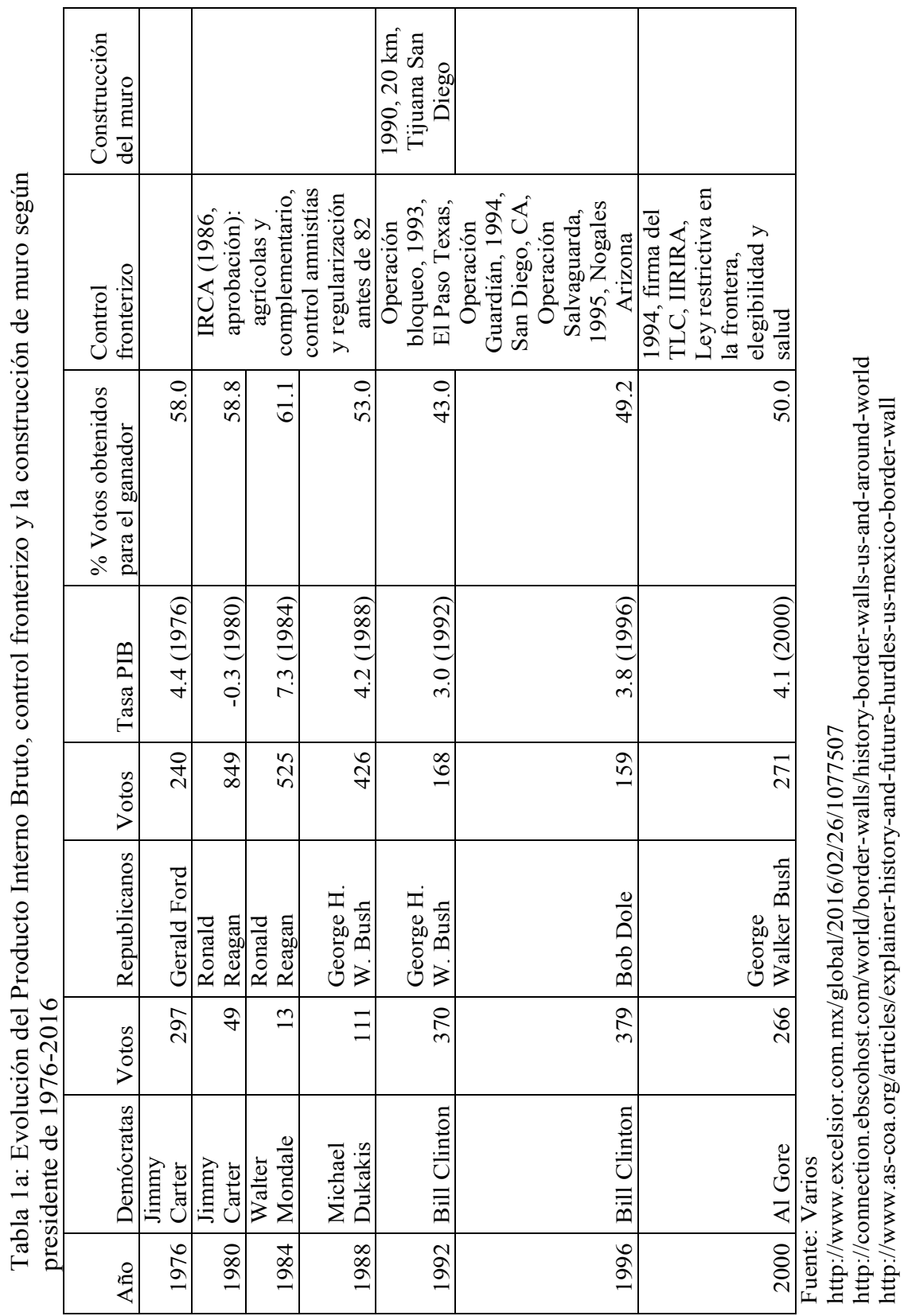


Tabla 1b: Evolución del Producto Interno Bruto, control fronterizo y la construcción de muro según presidente de 1976-2016 (continuación)

\begin{tabular}{|c|c|c|c|c|c|c|c|c|}
\hline Año & Demócratas & Votos & Republicanos & Votos & Tasa PIB & $\begin{array}{l}\% \text { Votos obtenidos } \\
\text { para el ganador }\end{array}$ & $\begin{array}{l}\text { Control } \\
\text { fronterizo }\end{array}$ & $\begin{array}{l}\text { Construcción } \\
\text { del muro }\end{array}$ \\
\hline 2004 & John Kerry & 251 & $\begin{array}{l}\text { George } \\
\text { Walker Bush }\end{array}$ & 286 & $2.8(2004)$ & 50.7 & $\begin{array}{l}\text { Operación Río } \\
\text { Grande, 1997, } \\
\text { Río Grande- } \\
\text { Texas }\end{array}$ & $\begin{array}{l}\text { 2006, } 557 \text { km, } \\
\text { Caléxico, } \\
\text { California, y } \\
\text { Douglas, } \\
\text { Arizona, 281 } \\
\text { km Laredo y } \\
\text { Brownsville, } \\
81 \text { kilómetros } \\
\text { de muros } \\
\text { entre Del Río } \\
\text { e Eagle Pass, } \\
140 \\
\text { kilómetros } \\
\text { entre El Paso } \\
\text { y Columbus, } \\
\text { Nuevo } \\
\text { México, 35 } \\
\text { kilómetros en } \\
\text { Tecate, } \\
\text { California } \\
\text { (Ley de valla } \\
\text { de Seguridad) }\end{array}$ \\
\hline 2008 & $\begin{array}{l}\text { Barack } \\
\text { Obama }\end{array}$ & 365 & John McCain & 173 & $-0.3(2008)$ & 67.8 & $\begin{array}{l}\text { Iniciativa } \\
\text { Mérida: } \\
\text { narcotráfico, } \\
\text { terrorismo y } \\
\text { seguridad } \\
\text { fronteriza }\end{array}$ & \\
\hline 2012 & $\begin{array}{l}\text { Barack } \\
\text { Obama }\end{array}$ & 332 & Mitt Romney & 206 & $2.3(2012)$ & 51.0 & $\begin{array}{l}\text { Redadas y } \\
\text { deportaciones }\end{array}$ & \\
\hline 2016 & $\begin{array}{l}\text { Hillary } \\
\text { Clinton }\end{array}$ & 232 & $\begin{array}{l}\text { Donald } \\
\text { Trump }\end{array}$ & 306 & $1.2(2016)$ & & $\begin{array}{l}\text { Deportaciones } \\
\text { masivas }\end{array}$ & $\begin{array}{l}\text { El } 25 \text { de enero } \\
\text { de } 2017 \text { el } \\
\text { presidente } \\
\text { estadunidense } \\
\text { Donald } \\
\text { Trump firmó } \\
\text { un decreto que } \\
\text { autorizó la } \\
\text { construcción } \\
\text { del muro }\end{array}$ \\
\hline
\end{tabular}

Fuente: Varios:

http://www.excelsior.com.mx/global/2016/02/26/1077507

http://connection.ebscohost.com/world/border-walls/history-border-walls-us-and-around-world

$\mathrm{http} / /$ www.as-coa.org/articles/explainer-history-and-future-hurdles-us-mexico-border-wall 


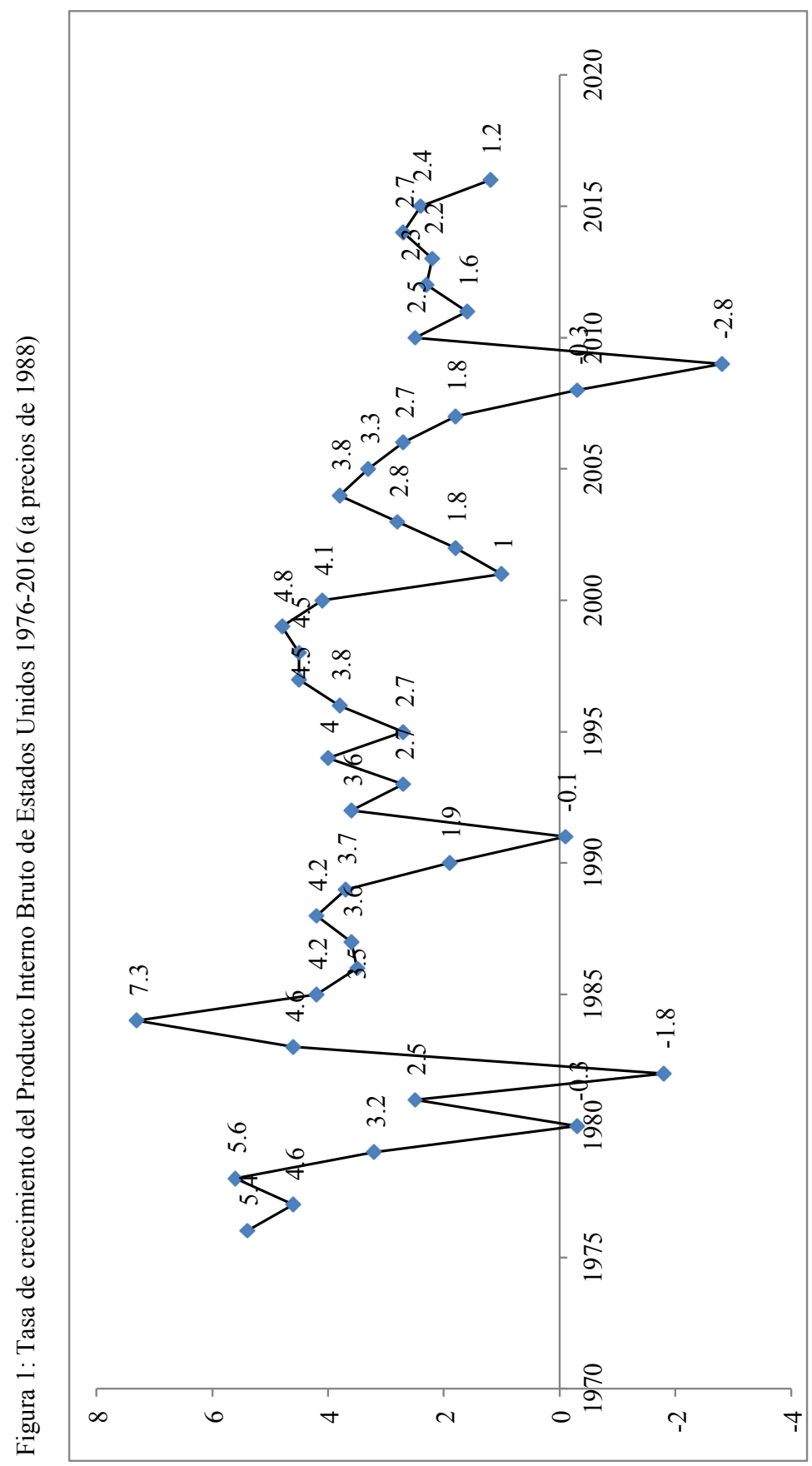

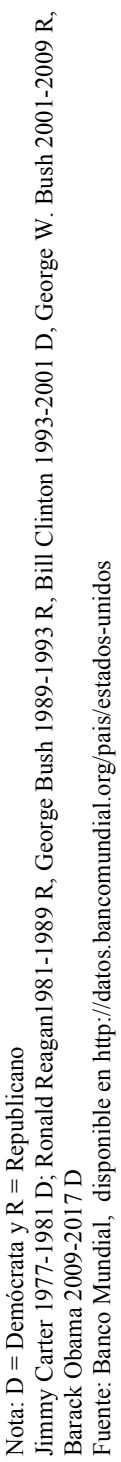


Ni la política fiscal ni la monetaria parecen jugar ningún papel importante para entender por qué la economía ha crecido más rápido con presidentes demócratas. Sin embargo, el Fondo Monetario Internacional (FMI) elevó sus proyecciones de crecimiento económico para Estados Unidos durante 2017 en 3.4 y para 2018 en 3.6 por ciento mayor al de 2016, que se estima fue de 1.2 por ciento (Figura 1), mientras Trump apoya medidas fiscales expansivas (a tal grado que las exportaciones mexicanas o las remesas monetarias serían gravadas para pagar el muro) ${ }^{11}$ recorte de impuestos y gasto en infraestructuras. ${ }^{12}$

El presidente Barack Obama realizó deportaciones y redadas silenciosas que llevaban implícitas sus dosis de política restrictiva. En cambio el actual presidente lo declara en la red y firma órdenes ejecutivas que tienen un efecto inmediato en la economía estadunidense.

A Donald Trump se le ha criticado tener una visión totalmente errática - con constantes cambios de opinión - en temas cruciales para la economía como en la inmigración, el muro en la frontera México-Estados Unidos, el Tratado de Libre Comercio de América del Norte (TLCAN), el Obamacare, el sistema de pensiones, entre muchos otros. Estas contradicciones han sido señaladas por muchos economistas y otros expertos; cada declaración del actual presidente de Estados Unidos crea una enorme incertidumbre económica para el mundo y sobre todo para México que es uno de los vecinos más cercanos y con la relación económica más estrecha.

\section{DeportaCión y DESEMPleo deSde Estados Unidos}

El argumento más socorrido para hacer posible la deportación es que los inmigrantes les quitan el trabajo a los nativos. Sin embargo, hay una gran cantidad de investigaciones académicas que han demostrado que los inmigrantes y los nativos viven un proceso desigual expresado en la segregación ocupacional, en una baja asimilación e integración por parte de los inmigrantes (Rodríguez, 2005). Por ejemplo, la desigualdad salarial entre inmigrantes latinoamericanos, mexicanos y nativos se mantiene en el tiempo independientemente de la rama y la ocupación (Caicedo, 2015).

${ }^{11}$ Véase en "Trump proposes big export taxe, triggering fight whith Mexico (20 por ciento)", disponible en http://www.eluniversal.com.mx/articulo/english/2017/01/26/trump-proposes-bigexport-tax-triggering-fight-mexico. Sin embargo, hay voces que sostienen que es un error gravar a México. Sobre esto véase "Gravar a México es un Plan ignorante: Krugman", disponible en http://www.eluniversal.com.mx/articulo/cartera/economia/2017/01/27/gravar-mexico-plan-ignorante-paul-krugman

${ }^{12}$ Véase en "Gastos de Trump ayudarán al crecimiento económico de EU: FMI", disponible en http://www.milenio.com/internacional/trump-fmi-gastos-estados_unidos-crecimiento-mercados-pronosticos-milenio-noticiasd_0_885511574.html 
En esta línea de ideas, investigaciones recientes han demostrado que la crisis financiera estadunidense ha repercutido en una disminución del empleo en sectores clave para los inmigrantes mexicanos (construcción, manufactura y alimentos); además ha tenido un efecto en el incremento del desempleo abierto de la población latina (históricamente es la más alta en relación a los nativos y asiáticos),$^{13}$ en la caída de los ingresos de los hogares de inmigrantes, y un creciente porcentaje de latinos que perciben un deterioro en sus condiciones de vida. Consecuentemente, la migración mexicana indocumentada empezó a mostrar síntomas de desaceleración desde 2006 y, más recientemente, el volumen de las remesas en cambio ha crecido por el temor a la deportación y depreciación del peso mexicano (Alarcón et al., 2008). En esta misma lógica autores como Salas, Loria y Díaz (2016), sostienen que la disminución del flujo migratorio de mexicanos a Estados Unidos desde 2005 se relaciona con el fortalecimiento de las acciones punitivas de Estados Unidos dirigido a la inmigración indocumentada, así como al aumento del desempleo sectorial y regional en Estados Unidos en relación con las tasas de desempleo en México (Salas, Loría y Díaz, 2016). Además, el índice de deportaciones es un factor poderoso y desalentador para la migración según Massey et al. (2009), y ello implica que un gran porcentaje de migrantes contratan los servicios de coyotes, debido a la creciente complejidad del cruce fronterizo.

\section{LAS DEPORTACIONES DE INMIGRANTES Y LA POLÍTICA MIGRATORIA}

Los antecedentes de la política restrictiva de la migración y la deportación se remontan al periodo entre 1921 y 1924 cuando fueron deportados 30 mil trabajadores mexicanos. El reparto de tierras en México ayudó a mitigar la angustia de estos deportados. El presidente Álvaro Obregón encabezó un programa de repatriación, el gobierno pagó los costos del ferrocarril para trasladar a los expulsados a sus lugares de origen. Las familias se movilizaron, surgieron organizaciones caritativas y la solidaridad marcó su retorno a territorio nacional (Massey et al., 2009).

La segunda ola de deportaciones inició con la mayor crisis económica en Estados Unidos. Entre 1929 y 1939 fueron deportados 500 mil mexicanos, se les llamaba repatriados; a este periodo se le bautizó como "era de las deportaciones". Entre 1929 y 1932 fueron deportados 5 mil trabajadores al mes; de 1935 a 1937 la cifra disminuyó a mil 200 repatriados mensualmente, en el año de 1939 los deportados fueron 20 mil, muchos de ellos acompañados por sus hijos que eran ciudadanos americanos. Para

\footnotetext{
${ }^{13}$ Véase en https://www.bls.gov/
} 
el año de 1940, la población mexicana en Estados Unidos se redujo a tan sólo 377 mil personas, una cantidad menor incluso que la que se registró en 1920, cuando empezaba a subir la marea de la migración (Massey et al., 2009).

Lázaro Cárdenas puso en marcha proyectos de colonización que acogieron a los deportados en Guerrero, Oaxaca y en la frontera norte, en Mexicali, Matamoros y Tamaulipas. Los mexicanos que se quedaron en Estados Unidos tuvieron grandes dificultades, perdieron casas, escuelas, trabajos, algunos fueron reclutados también para la guerra y fueron al frente de batalla durante la Segunda Guerra Mundial. ${ }^{14}$

Con el fin de la guerra de Corea (1953) regresaban miles en busca de trabajo, pero se comenzó a culpar a los inmigrantes del desempleo y el ambiente se tornó caldeado y turbulento, con creciente discriminación, agresiones y crímenes de odio.

Entre 1950 y 1954 fueron deportados tres millones 500 mil mexicanos. El programa de deportaciones se llamó "Espalda Mojada". México enfrentó el retorno de mexicanos cuando la economía crecía a un ritmo de seis por ciento anual (Bustamante, 1973).

La política migratoria del gobierno de Bill Clinton se caracterizó por los cierres de la frontera con México en gran parte de California y Texas, los estados con más mexicanos y con más migración. A partir de 1993 se inició la construcción de muros y se endureció el control migratorio con la Operación Bloqueo (Cd. Juárez-El Paso 1993), Operación Guardián (Tijuana-San Diego, 1994), Operación Salvaguarda (Yuma-Tucson 1995) y Operación Río Grande (Texas-Nuevo México, 1997). Estados Unidos cerró los cruces menos peligrosos y estableció controles más rígidos (véase Tabla 1a, Tabla 1b y Figura 2).

Los atentados del 11 de septiembre de 2001 (11-S) pusieron en alerta la frontera con México. El gobierno de George W. Bush fortaleció los controles migratorios, las detenciones y las deportaciones. Dos ejemplos: en 2003 se puso en marcha el programa US Customs and Border Protection (Aduanas y Protección Fronteriza), operativo para deportar inmigrantes en puntos distantes a los de su entrada. Fueron deportados 5,600, a un ritmo de 300 al día, esposados, amarrados, como delincuentes, subidos a un avión y dejados en lugares distantes y desconocidos, sin relaciones, sin dinero, sin familia (véase Tabla 1a, Tabla 1b y Figura 2).

${ }^{14}$ Véase en México-Estados EU historia de migración y deportación disponible en http://www. eluniversal.com.mx/entrada-de-opinion/columna/enriqueta-cabrera/mundo/2017/01/22/mexicoeu-historia-de-migracion-y 


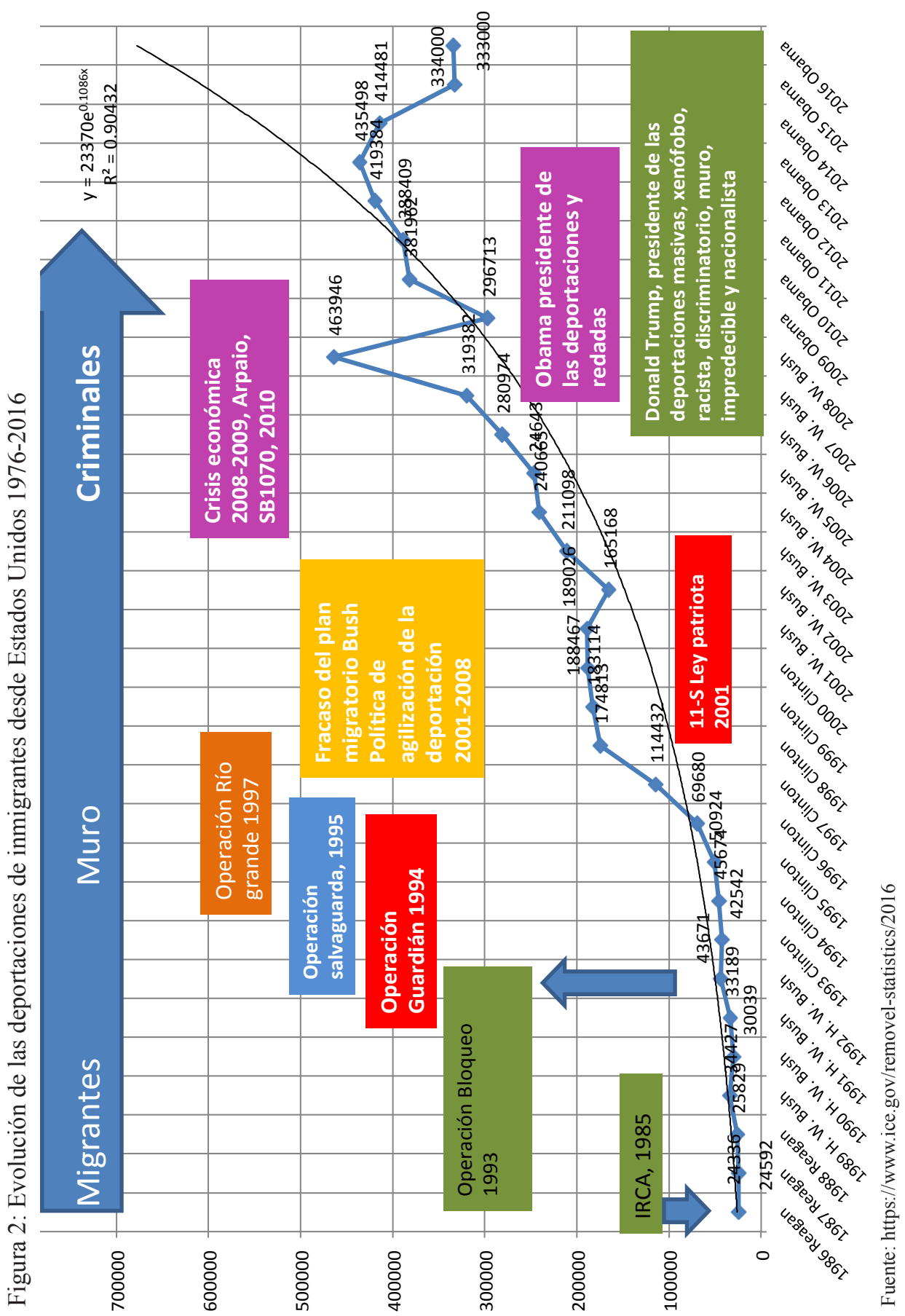


La inmigración de indocumentados se mantuvo estable alrededor de 11 y 12 millones de acuerdo con Pew Research Center y el Buró del Censo de Estados Unidos durante el gobierno del demócrata Barack Obama. Sin embargo, durante su gobierno las deportaciones alcanzaron el nivel más alto: Barack Obama deportó a 2.8 millones (por lo que se le llamó “deportador en jefe"); George W. Bush 2.2 millones y Bill Clinton 870 mil (véase Figura 2).

Estudios realizados por diversos grupos interesados con los indocumentados han mencionado que deportar a todos los indocumentados que se calculan entre 11 y 12 millones tendría un costo gigante para el país, ya que no todos los involucrados son mexicanos y todas las deportaciones serian vía aérea. Algunos escépticos llaman a esta deportación masiva una utopía. $^{15}$

Sin embargo, el presidente Trump ha firmado decretos ejecutivos que van más allá de la construcción del muro en la frontera con México, los cuales son:

- Muchos inmigrantes que entran ilegalmente o que se quedan en el país una vez caducados sus visados suponen una amenaza significativa para la seguridad nacional.

- Las ciudades santuario han causado un daño inconmensurable al pueblo estadunidense y la fundación de nuestra República.

- El aumento reciente de la inmigración ilegal en la frontera sur con México ha puesto una carga innecesaria en el presupuesto federal.

- Entre quienes entran ilegalmente se encuentran los que buscan dañar a los estadunidenses mediante actos de terrorismo o criminales.

- La inmigración ilegal presenta una amenaza constante a los intereses de Estados Unidos. ${ }^{16}$

Esto significa que empieza a cumplir las promesas electorales comprometidas en su campaña al considerar empezar a deportar a inmigrantes irregulares. ${ }^{17}$ Aquí es donde empieza el cuestionamiento al anterior presidente Barack Obama que durante su administración deportó a 2.8 millones de inmigrantes. ${ }^{18}$ Esta cifra es mucho mayor que los deportados por George

\footnotetext{
${ }^{15}$ Véase en "Deportaciones masivas una utopía", disponible en http://www.oltarsh.com/spanishsite/deportaciones-masivas-una-utopia.php

${ }^{16}$ Véase en "Qué dicen los decretos de inmigración de Trump", disponible en http://internacional.elpais.com/internacional/2017/01/25/estados_unidos/1485380387_624588.html

17 Véase en "Donald Trump promete deportar hasta tres millones de inmigrantes irregulares", disponible en http://internacional.elpais.com/internacional/2016/11/13/actualidad/1479054583_555103.html

${ }^{18}$ Véase en "Con 2.8 millones, Obama es el que más ha deportado indocumentados", disponible en http://www.elfinanciero.com.mx/nacional/con-millones-obama-es-el-que-mas-ha-deportado-
} 
Bush hijo, ya que las deportaciones hechas por él fueron de 2.2 millones de personas, pero juntos son los presidentes que más inmigrantes deportaron: cinco millones (véase Figura 2). Dichas deportaciones en su mayoría fueron de mexicanos, que representaban alrededor de 73 por ciento entre 2014 y $2015 .^{19}$

Independientemente del partido político que llegue a la presidencia en Estados Unidos han creado iniciativas para deportar y aplicar redadas contra inmigrantes indocumentados tal como se ha citado anteriormente (véanse Tabla 1a y Tabla 1b). ${ }^{20}$ Este acto, según la Comisión Interamericana de Derechos humanos, implica una violación de los derechos humanos de los inmigrantes capturados y deportados. ${ }^{21}$

Simultáneamente a las deportaciones tenemos que también ha aumentado el porcentaje de naturalización en los tres últimos periodos gubernamentales, con independencia de la tendencia de la administración: demócrata o republicana, ¡qué paradoja!

La legalización y la migración clandestina de 1986 a la fecha, con la puesta en marcha de la Immigration Reform and Control Act (IRCA), se inició un proceso de amnistía para los inmigrantes indocumentados que vivían en Estados Unidos, lo que permitió la legalización de 2.3 millones de personas; además, se crearon programas de trabajadores especiales (las visas H). Junto con la legalización, se generó un proceso de migración clandestina para responder a la creciente demanda de mano de obra. ${ }^{22}$

Sin embargo, hoy ha cambiado la historia, a raíz de las órdenes ejecutivas de Donald Trump, las cuales ya han empezado a sentir sus efectos y el ejemplo emblemático que han posicionado los medios es el de Guadalupe García sobre los deportados Dreamers, que ha conducido a una psicosis a tal grado de llegar al suicidio. Como estos ejemplos, las instituciones de México no encuentran respuesta para negociar con Estados Unidos en relación al tema migratorio, al impuesto a las remesas, la construcción del muro.

\footnotetext{
indocumentados.html

${ }_{19}$ Véase en "Mexicanos, el mayor grupo de deportados con Obama en 2015", disponible en http://www.excelsior.com.mx/global/2016/12/18/1135078

${ }^{20}$ Para ello se podrá revisar que en 38 entidades en Estados Unidos cuentan con leyes totalmente en contra, contra migrantes y en otras poco amigables. El resto cuentan con leyes amigables o algo amigables, véase en http://observatoriocolef.org/

${ }^{21}$ Véase en "Informe sobre inmigración en estados unidos: detenciones y debido proceso", disponible en http://cidh.org/countryrep/USImmigration.esp/Cap.IV.b.htm

${ }_{22}^{2}$ Véase en "México - Síntesis histórica de las migración internacional en México", disponible en http://www.migracionoea.org/index.php/es/sicremi-es/17-sicremi/publicacion-2011/paiseses/128-mexico-1-si-ntesis-histo-rica-de-las-migracio-n-internacional-en-me-xico.html
} 
Modelo multivariante para la explicación de las deportaciones de migrantes... / R. CRUZ y JG. GONZÁLEZ

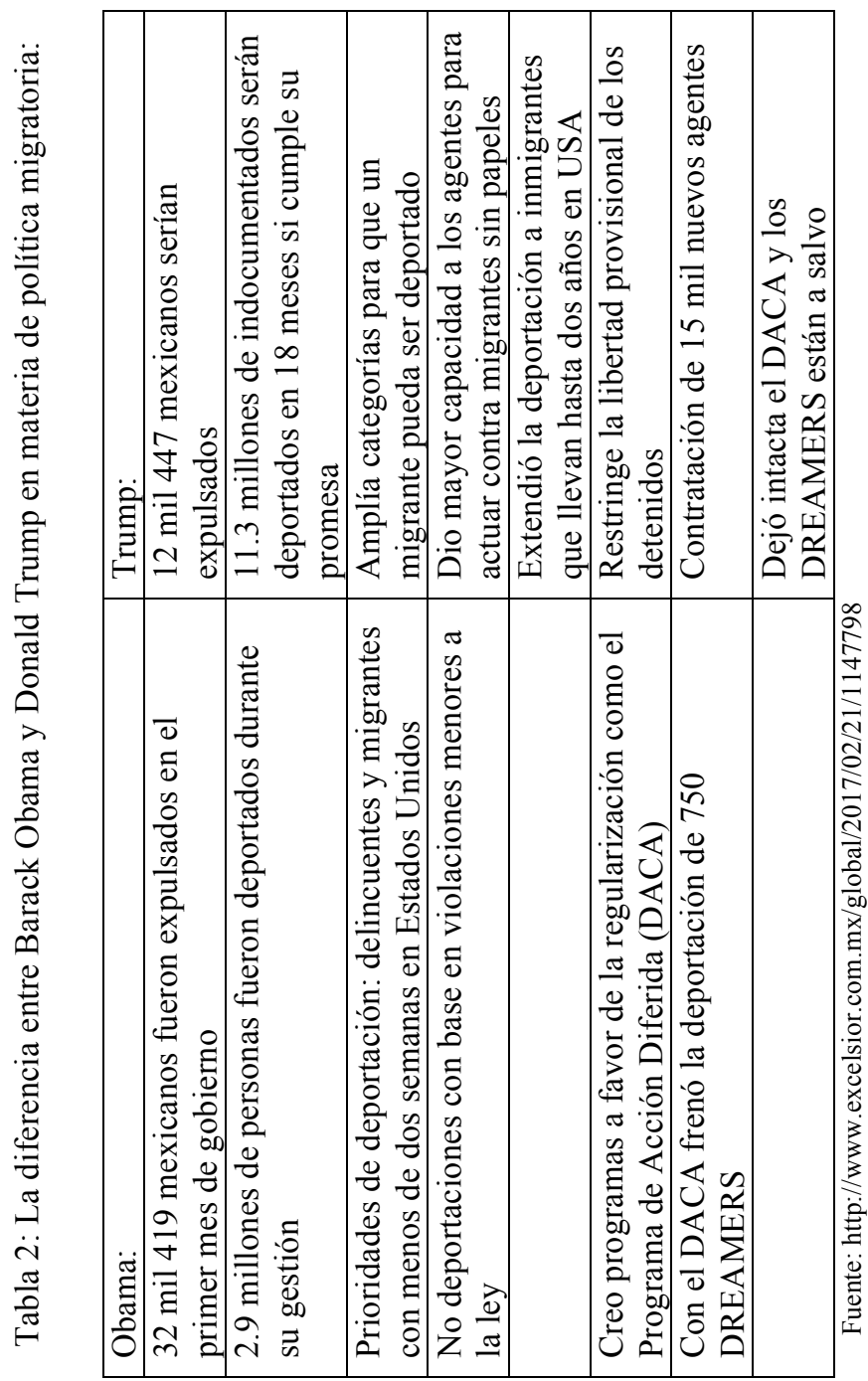


Esto marca la diferencia entre Obama y Trump en materia de política migratoria (véase Tabla 2) pero en adelante tiene una gran cantidad de propuestas políticas para restringir la entrada de inmigrantes indocumentados.

Hoy se dice que las deportaciones cambiarán el sistema migratorio y hará que en México se incrementen las solicitudes de asilo de inmigrantes de distintas partes del mundo; con ello se rompe la narrativa anterior para poder entender la construcción de un nuevo sistema migratorio derivado de la política migratoria estadunidense en la cual se criminaliza a la inmigración indocumentada. ${ }^{23}$ Esto se verá expresado en el primer año de la gestión de Trump en el cual se podrían duplicar las deportaciones, de 350 mil anuales a casi 700 mil. $^{24}$

\section{MÉTOdo Y FUENTES DE INFORMACIÓN}

\section{Fuente de información}

Para este trabajo hemos hecho uso de fuentes de información mixta como datos de las deportaciones obtenidos de la Official Website of the Department of Homeland Security (ICE), ${ }^{25}$ el Producto Interno Bruto derivado del Banco Mundial, la tasa de desempleo del United States Department of Labor. ${ }^{26}$ Vale la pena mencionar que algunos datos se estimaron a partir del método de interpolación para completar la serie (Manzur, 2009) y hacer posible el modelo de regresión múltiple.

\section{Modelo econométrico: regresión múltiple}

Las variables económicas de las relaciones trasnacionales de la migración suelen presentar multicorrelaciones. Por ejemplo, para estudiar la relación entre las deportaciones y la actividad real de la economía de Estados Unidos se puede plantear un modelo de Regresión Lineal Simple (RLS), sin embargo, las deportaciones pueden depender también de otras variables como el desempleo, la política migratoria u otras (Gujarati, 2000).

Si para cada valor en las deportaciones, las demás variables se distribuyen aleatoriamente, la estimación por RLS es adecuada y la variación "debida" a las otras variables estaría incluida en la variación aleatoria alrededor de la regresión, pero en caso contrario la estimación sería incorrecta,

\footnotetext{
${ }^{23}$ Véase en "Migración México - EU sufrirá cambios drásticos a futuro, aseguran especialistas", disponible en http://oncenoticias.tv/index.php?modulo=interior\&nota=127\&dt=2016-12-19

${ }^{24}$ Véase en "Doble reto, incorporar el tema migratorio en la revisión del tratado, opina académico en foro", disponible en http://www.jornada.unam.mx/2017/01/24/politica/008n2pol

${ }^{25}$ Véase en https://www.ice.gov/. Cabe aclarar que a partir de 2011 cambia el concepto de extranjero deportado por el de aprehensiones de extranjeros pero que en el fondo es lo mismo.

${ }^{26}$ Véase en https://www.dol.gov/
} 
si por ejemplo, las políticas migratorias variaran según origen de partido del presidente y ésta influyera en la deportación, una parte no cuantificada de la variación de la deportación que el modelo atribuye al comportamiento económico sería "debido" a la política del presidente en turno.

La regresión lineal múltiple (RLM) es un modelo que permite estudiar estas causas entre 1995 y 2016. Esta división obedece a que en ellos ocurren cambios estructurales de la economía estadunidense y mexicana derivada del Tratado de Libre Comercio (TLC). Por tanto el modelo se expresan en:

$$
\mathrm{Y}=\beta_{0}+\beta_{1} \mathrm{X}_{1}+\beta_{2} \mathrm{X}_{2}+\xi
$$

$\beta_{0}$ : media de $Y$ cuando todas las $X_{\mathrm{i}}$ son cero (cuando no tiene sentido $\mathrm{X}_{\mathrm{i}}=0$, Por ejemplo, pibabs, se interpreta como la media de $Y$ que no depende de las $\mathrm{X}_{\mathrm{i}}$ ).

$\beta_{\mathrm{i}}$ : cambio en la media de $Y$ cuando $X_{\mathrm{i}}$ aumenta una unidad permaneciendo constantes las demás.

Entonces $\mathrm{Y}=$ Deportaciones, $\mathrm{X}_{1}=$ pibabs; $\mathrm{X}_{2}=$ desempleousa.

La estimación de los coeficientes también se hace por mínimos cuadrados o máxima verosimilitud y se obtienen los mismos resultados. Teniendo presente lo anterior, cabe mencionar que los modelos de regresión múltiple se realizaron con el paquete estadístico de Statistical Package for the Social Sciences (SPSS 21).

Pero antes de pasar al modelo de regresión múltiple revisaremos algunas pruebas de hipótesis de tipo estadístico:

Linealidad: observemos las deportaciones, que es la variable dependiente, tenemos que con el pibasb (producto interno bruto a precios de 2008 de Estados Unidos) está muy asociada porque tiene doble asterisco (a 99 por ciento) y con el desempleo en Estados Unidos también está asociada con 95 por ciento. Esto ya es un detalle importante para ser tomados en cuenta para el modelo de regresión múltiple. Entre las dos independientes podemos observar que no hay asociación lineal. Por tanto estamos ante la ausencia de colinealidad y no hay problema con el modelo (Tabla 3).

Hipótesis de la normalidad: en este caso se usa el de Shapiro-Wilk porque incluye menos de 50 casos y para ello la variable dependiente, es decir, la de deportados cumple con los requisitos de la normalidad. Porque el p-value es mayor a 0.05 (Tabla 4). 
Tabla 3: Correlaciones

\begin{tabular}{lrrr}
\hline & Deportados & Desempleousa & Pibabs \\
\hline Deportados & & & \\
Correlación de Pearson & 1 & $0.510^{*}$ & $0.805^{* *}$ \\
Sig. (bilateral) & & 0.015 & 0.000 \\
$\mathrm{~N}$ & 22 & 22 & 22 \\
Desempleousa & & & \\
Correlación de Pearson & $0.510^{*}$ & 1 & 0.308 \\
Sig. (bilateral) & 0.015 & 22 & 0.163 \\
$\mathrm{~N}$ & 22 & & 22 \\
Pibabs & & 0.308 & \\
Correlación de Pearson & $0.805^{* *}$ & 0.163 & \\
Sig. (bilateral) & 0.000 & 22 & 22 \\
$\mathrm{~N}$ & 22 & & \\
\hline
\end{tabular}

*. La correlación es significante al nivel 0,05 (bilateral).

**. La correlación es significativa al nivel 0,01 (bilateral).

Fuente: Elaboración propia con base en Official Website of the Department of Homeland Security (ICE), el Banco Mundial y el United States Department of Labor.

Tabla 4: Pruebas de normalidad

\begin{tabular}{lllllll}
\hline \multicolumn{4}{c}{ Kolmogorov-Smirnov $^{\mathrm{a}}$} & \multicolumn{3}{c}{ Shapiro-Wilk } \\
\hline & Estadístico & gl & Sig. & Estadístico & gl & Sig. \\
\hline Deportados & 0.109 & 22 & $0.200^{*}$ & 0.963 & 22 & 0.561 \\
\hline *. Este es un límite inferior de la significación verdadera. & & & \\
a. Corrección de la significación de Lilliefors \\
$\begin{array}{l}\text { Fuente: Elaboración propia con base en Official Website of the Department of Homeland } \\
\text { Security (ICE), el Banco Mundial y el United States Department of Labor. }\end{array}$
\end{tabular}

Prueba de independencia. en el modelo se puede afirmar que el DurbinWatson cuyo valor es de 2.117, satisface la hipótesis de independencia porque su valor es mayor a dos lo cual indica que los residuales son independientes (independencia de errores, véase Tabla 5). ${ }^{27}$

Varianza de las $x$ 's distintos de cero: para el modelo de regresión probado con las dos variables independientes se explica el 69.5 por ciento de la varianza de la variable dependiente ( $\mathrm{r}$ cuadrado 0.695) (Tabla 5).

ANOVA: las dos variables al tiempo están prediciendo la variable dependiente, es decir, hay una significancia por debajo de 0.05 por ciento. Por tanto la hipótesis es que mejora significativamente la predicción de la variable dependiente (deportados).

\footnotetext{
${ }^{27} \mathrm{Si}$ el valor se encuentra entre 1 y 3 aceptamos el supuesto de la independencia de los errores.
} 
Modelo multivariante para la explicación de las deportaciones de migrantes... / R. CRUZ y JG. GONZÁLEZ

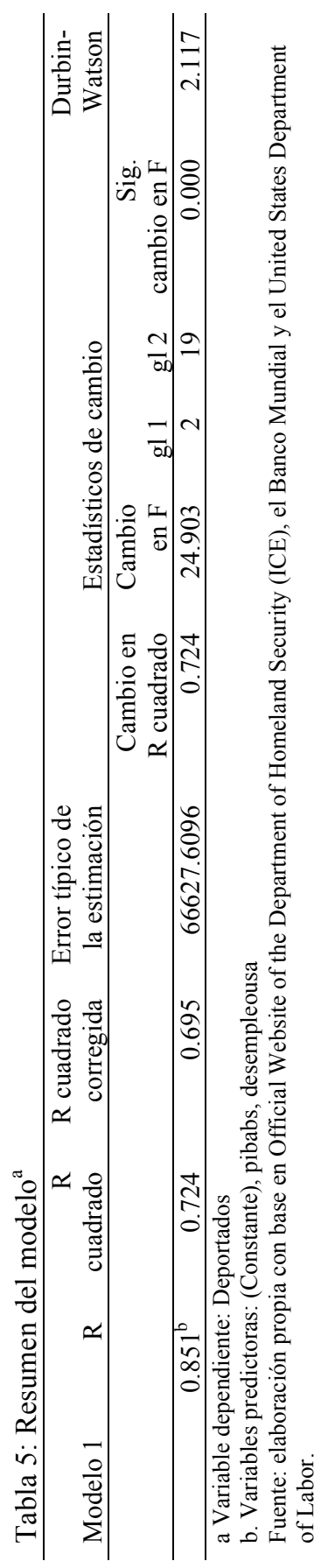


Por tanto, las variables incluidas nos indican que es un buen modelo de predicción de la variable dependiente. El resto de las pruebas de hipótesis serán probadas durante el texto como el de los errores de las $x$ 's son ceros: $\mathrm{E}\left(\mathrm{et} / \mathrm{x}^{\prime} \mathrm{s}\right)=0$ y la de las $x^{\prime} s$ dadas no son aleatorias. Pero en términos generales las pruebas aquí presentadas permiten la corrida del modelo.

\section{DETERMINANTES DE LAS DEPORTACIONES DE INMIGRANTES INDOCUMEN- TADOS DESDE ESTADOS UNIDOS 1995-2016}

El modelo de regresión múltiple tiene el propósito de desmitificar las dimensiones de la deportación y su relación con el crecimiento económico y el desempleo. Se toman los datos derivados de distintas fuentes de información para estudiar dicha causalidad macroeconómica de las deportaciones. Para este ejercicio decimos que la variable dependiente es estocástica y las independientes no (Gujarati, 2000) (Tabla 6). La información es combinada o mixta y se usan indicadores relativos y absolutos para corregir la colinealidad, la heteroscedasticidad y autocorrelación.

Tabla 6: Variables introducidas/eliminadas ${ }^{\mathrm{a}}$

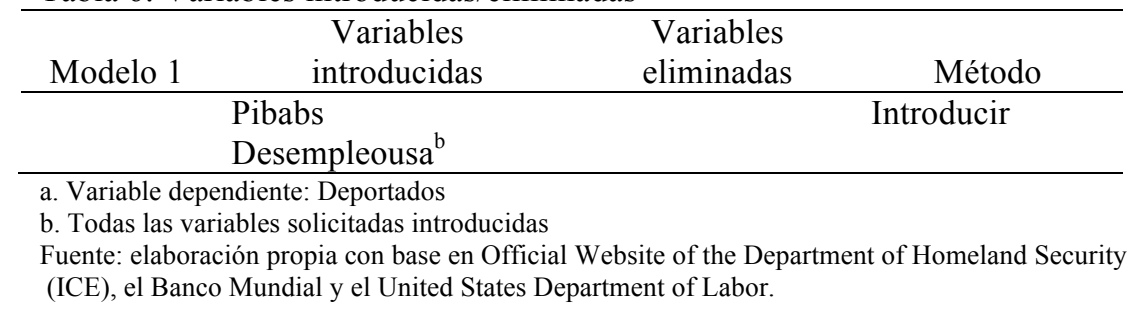

\section{Bondad del ajuste}

En conjunto las dos variables explicatorias incluidas en el análisis de las deportaciones explican 69. 5 por ciento de la varianza de la variable dependiente, pues $\mathrm{R}$ cuadrado corregida es igual a 0.695. Además el error típico ha disminuido en 66627.6 lo que indica que es el mejor. Cabe notar que el valor corregido de $\mathrm{R}$ cuadrado no es igual al no corregido para el modelo, pero sí para el R cuadrado y el cambio en R cuadrado (Tabla 5).

El $\mathrm{F}$ estadístico contrasta la hipótesis nula de que el valor poblacional de $\mathrm{R}$ es cero, por tanto, nos permite decidir si existe relación lineal significativa entre la variable dependiente (Deportados) y las variables tomadas en conjunto o en términos simples decimos que las variables pibas y desempleousa explican las deportaciones actuales). El valor del nivel crítico Sig. $=0.000$ indica que sí existe relación lineal significativa. Por tanto, 
podemos afirmar que el hiperplano definido por la ecuación de regresión ofrece un buen ajuste en la nube de puntos para el modelo. Pero además el Durbin-Watson es ligeramente mayor a 2 para el modelo. ${ }^{28}$ Para el caso del ANOVA se dice que $F(2,21)=24.903 \leq 0.005$ y lo cual indica que existe una relación significativa entre deportados y las variables pibabs y desempleousa (Tabla 7).

\begin{tabular}{lrrrrr}
\multicolumn{2}{l}{ Tabla 7: ANOVA $^{\mathrm{a}}$} \\
\hline Modelo 1 & Suma de cuadrados & gl & Media cuadrática & $\mathrm{F}$ & Sig. \\
\hline Regresión & 221099670660.110 & 2 & 110549835330.055 & 24.903 & $0.000^{\mathrm{b}}$ \\
Residual & 84345529047.208 & 19 & 4439238370.906 & & \\
Total & 305445199707.318 & 21 & & & \\
\hline
\end{tabular}

a. Variable dependiente: Deportados

b. Variables predictoras: (Constante), desempleousa, pibabs

Fuente: elaboración propia con base en Official Website of the Department of Homeland Security

(ICE), el Banco Mundial y el United States Department of Labor.

\section{La ecuación de regresión 1}

La tabla de coeficientes de regresión parcial contiene la información para construir la ecuación de regresión mínimo-cuadrática. En la columna encabezada por coeficientes no estandarizados se encuentra los coeficientes $\left(\beta_{\mathrm{k}}\right)$ que forman parte de la ecuación de puntuaciones directas (Tabla 8).

\section{Modelo de regresión 1}

Pronóstico en las deportaciones $($ Deportados $)=-76,863.411$ (Constante $)+$ 0.018 (pibabs) $+20,864.510$ (desempleousa) $+\xi$

Estos coeficientes no estandarizados se interpretan en los términos siguientes: el intercepto de la línea indica el nivel promedio del crecimiento de las deportaciones cuando el conjunto de las variables es cero y tiene un valor de -76,863. El coeficiente correspondiente a la variable tasa de crecimiento del (pibabs) que vale, 0.018 e indica que, si el resto de los valores ceteris paribus, a un aumento en una unidad en el PIB (o su variación), le corresponde en promedio, un aumento de 0.018 a las deportaciones entre 1995 y 2016. Este es consistente con los planteamientos macroeconómicos que sostienen que, si el signo es positivo estaramos ante una mayor deportación de personas. ${ }^{29}$

\footnotetext{
${ }^{28}$ A partir de nuestros datos rechazamos la hipótesis de que hay correlación serial positiva en los residuales. Es decir no hay autocorrelación en el modelo.

${ }^{29}$ En caso contrario estaríamos hablando de una menor deportación.
} 


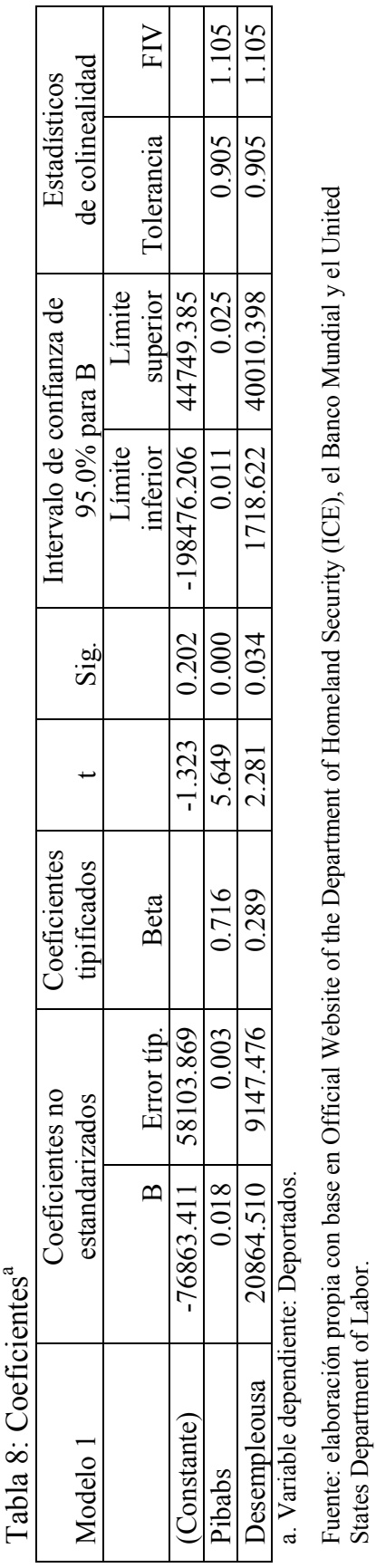


Asimismo, el coeficiente de la variable tasa de desempleo en Estados Unidos (desempleousa) por ser positiva en el modelo indica que hay una relación directa sobre las deportaciones (véase Tabla 5).

\section{Coeficientes de regresión estandarizados}

Respuesta a nuestra ecuación. Los coeficientes betas están basados en puntuaciones típicas, y por tanto, son directamente comparables entre sí. Indican cantidad de cambios en puntuaciones típicas, que se producirán en la variable dependiente (deportaciones) por cada cambio en una unidad en la correspondiente variable independiente (manteniendo constante el resto de las variables independientes). En términos simples, para el modelo aquí estimado, por cada unidad de cambio en las variables independientes (pibabs y desempleousa) la deportación fue de 0.003 y 9147.4761, respectivamente (Tabla 5).

Los coeficientes proporcionan una pista muy útil sobre la importancia relativa de cada variable independiente en la ecuación de la regresión. En general, una variable tiene tanto peso (importancia) en la ecuación de la regresión cuanto mayor (en valor absoluto) es su coeficiente de regresión estandarizado. Observado los coeficientes Beta de la Tabla 8 vemos que la variable desempleo es la más importante para explicar la variación de las deportaciones, le sigue la del pibabs. Por tanto aquel que aporta una mayor explicación en la deportación es el desempleo y la variación de pibabs estadunidense. Lo que se ha dicho anteriormente sobre la no independencia de los coeficientes de regresión parcial no estandarizada, también vale aquí.

\section{Prueba de significación}

Los valores de $t$ y la significancia hacen referencia a qué tanto podemos generalizar sobre los deportados y que tanto le está aportando el modelo de predicción. Para los coeficientes del modelo de regresión las puntuaciones $t$ indican que las variables incluidas en el modelo aportan significativamente al modelo de predicción. Lo que indica los valores obtenidos se pueden generalizar a la población deportada. Entonces 5.649 y 2.281 ; $\mathrm{p}<0.05$. Este es otro elemento para corroborar que es un buen modelo, es decir, que no hay una variable que sobre para predecir el modelo de las deportaciones desde Estados Unidos. Pero, una de ellas (variable explicatoria) en el modelo contribuye de forma significativa a explicar lo que ocurre en la variable dependiente (Deportados Tabla 8). ${ }^{30}$

${ }^{30}$ Por tanto, la variable tipo de cambio es 0.716 (pibabas) $/ 0.289$ (desempleouss) $=2.47$ veces más importante que la variable desempleousa. Esto indica que el coeficiente más potente es del 


\section{Otros supuestos del modelo de regresión lineal}

Los supuestos de un modelo estadístico de regresión se refieren a una serie de condiciones que deben darse para garantizar la validez del modelo. Dichos supuestos son de linealidad (revisado anteriormente), homocedasticidad, normalidad (modelo asimétrico), la media de los residuos se pudo corroborar que vale cero y no la no existencia de colinealidad (Gujarati, 2000). Sobre este último podemos decir que los estadísticos de colinealidad: nuevamente no tenemos un valor de significancia, por tanto, la interpretación se debe de hacer en relación al valor que se está obteniendo. Se debe buscar que los valores estén cercanos a uno. Lo que podemos observar es que los rangos son similares (que también podrían ser diferentes) en el factor de varianza inflada (FIV), lo que nos indica que se cumple con el supuesto de no multicolinealidad entre las variables (valores de 1.05 para ambas variables independientes). A la vez podemos decir que no hay un valor por encima de diez y en conjunto todos los valores cercanos a uno. En términos generales podemos afirmar que es un buen modelo para predecir las deportaciones.

\section{Comentarios finales}

En términos del discurso pareciera ser que las deportaciones y el comportamiento de los ciclos económicos estadunidenses tienen una relación según origen de partido del presidente en el poder. Asimismo, las deportaciones pueden depender del comportamiento de la tasa de desempleo estadunidense, pero también dependen de otras variables como la de la política migratoria, etcétera.

Esto parece ser consistente con argumentos de investigadores sobre el tema los cuales han dicho que "El impacto de las deportaciones de mexicanos se da en el contexto de la crisis financiera, el impacto de la crisis en el empleo y las condiciones de vida de los inmigrantes y los latinos en Estados Unidos". Pero además tiene implicaciones en la desaceleración de la migración indocumentada y caída de las remesas. ${ }^{31}$

Los resultados derivados del modelo de regresión múltiple, cumplen con los supuestos e hipótesis planteadas, en términos generales, las cuales se pudieron probar a través de las interrelaciones con variables incluidas en el modelo de regresión múltiple para explicar las deportaciones des-

pibabs.

${ }^{31}$ Véase en lo que hemos escrito en secciones precedentes y a la vez en el link que aquí se pone: https://www.colef.mx/evento/la-crisis-financiera-en-estados-unidos-y-su-impacto-en-lamigracion-mexicana/ 
de Estados Unidos. Porque la mayoría de los test estadísticos pasaron la prueba y sobre todo el de normalidad, y $p$-value entre otras. En general las hipótesis estadísticas que se pide en todo modelo de regresión múltiple. Tal como lo afirma Karl Popper, "Pero esto no implica que no sean refutadas las hipótesis. Si ha de formar parte de la ciencia, una hipótesis ha de ser falsable o refutable." 32

Pero también, permitió probar los argumentos teóricas de la relación entre las deportaciones y los comportamientos macroeconómicos sobre los cuales se toman decisiones en materia de política migratoria. Esto lo podemos observar en la Tabla 1a, Tabla 1 b y Figura 2. Pero además en el discurso del actual presidente estadunidense con sus agregados de seguridad, xenofobia y racismo. En la Figura 2, la variable tiempo, en su caso, tiene un "mayor poder de explicación" dado que contiene una sucesión de hechos en materia de política restrictiva. Pero al incluirla al modelo de regresión múltiple reduce su poder explicativo y conduce a situaciones de colinealidad. Es por ello que se utilizó como un modelo de regresión lineal simple, aparte. Por otro lado, las variables de las remesas y el tipo de cambio se excluyeron porque fueron excluidos al ser corridos por eliminación y por pasos sucesivos.

Pero además, las deportaciones traen consigo el reto de entender el nuevo sistema migratorio que esto ocasionará en México, principalmente. Otro de los retos que vale la pena destacar es cómo insertar o reinsertar socialmente a los deportados en los lugares de destino, es decir, el regreso a México de manera voluntaria o involuntaria. Cómo reinsertar e insertarlos al mercado de trabajo, a la colonia o pueblo, a la escuela, a la cultura, a la participación política y social. ${ }^{33}$ Cómo atender la separación de madres e hijos. Cómo resolver la situación de los deportados que compraron casa en Estados Unidos; 45 por ciento de los migrantes y siete de cada diez paga hipoteca. Cómo resolver la situación de muchos porque son nacidos en Estados Unidos (en términos de la doble nacionalidad) y sólo hablan inglés, aquí el reto más importante es que se integren culturalmente a la sociedad mexicana que no solo implica un buen discurso político. Implica tener oportunidades reales en múltiples dimensiones de la continuidad del retornado voluntario o deportado. Este concepto cambia la lectura de un retorno voluntario a uno forzado por la política restrictiva en Estados Unidos.

\footnotetext{
32 Véase en "Las teorías científicas según Karl Popper: La Falsabilidad", disponible en http:// www.madrimasd.org/blogs/universo/2007/02/10/59009

${ }^{33}$ Esto significa hacer valida algunas de las propuestas incluidas en el decreto por el que se aprueba el Programa Especial de Migración 2014-2018, disponible en http://www.politicamigratoria. gob.mx/es_mx/SEGOB/Programa_Especial_de_Migracion_2014-2018_PEM
} 


\section{REFERENCIAS BIBLIOGRÁFICAS}

Alarcón, Rafael, Cruz, Rodolfo, Díaz-Bautista, Alejandro, González-König, Gabriel, Izquierdo, Antonio, Yrizar, Guillermo y Zenteno, René, 2008, La crisis financiera en Estados Unidos y su impacto en la migración mexicana, disponible en https://www.colef.mx/evento/la-crisis-financiera-en-estados-unidos-y-su-impacto-en-la-migracion-mexicana/

Banco Mundial, 2016, Estados Unidos, disponible en http://datos.bancomundial. org/pais/estados-unidos

Biblioteca Digital Mundial, s/f, Línea histórica: Historia de los Estados Unidos, disponible en https://www.wdl.org/es/sets/us-history/timeline/

Blinder, Alan S. y Watson, Mark W., 2014, Presidents and the U.S. Economy: An Econometric Exploration, Woodrow Wilson School and Department of Economics Princeton University, disponible en https://www.princeton.edu/ mwatson/ papers/Presidents_Blinder_Watson_July2014.pdf

Bustamante, Jorge, 1973, La política de inmigración de Estados Unidos: un análisis de sus contradicciones, disponible en http://codex.colmex.mx:8991/exlibris/ aleph/a18_1/apache_media/UG3XL3MVUG3SVIMMK3IHXUAANNRG94.pdf

Caicedo, Maritza, 2015, La desigualdad salarial entre inmigrantes latinoamericanos y nativos en Estados Unidos (1980-2010), disponible en http://www.sciencedirect.com/science/article/pii/S1870355016300143

Cuberes, David, 2016, Presidentes y economía en Estados Unidos, disponible en http://nadaesgratis.es/david-cuberes/presidentes-y-economia-en-estados-unidos

Durand, Jorge, y Arias, Patricia, 2000, La experiencia migrante: iconografía de la migración México-Estados Unidos, Altexto, México.

Gamio, Manuel, s/f, El migrante mexicano: la historia de su vida. Entrevistas completas, 1926-1927. UC-MEXUS, CIESAS, PORRÚA e INM

Gujarati, Damodar N., 2000, Econometría, Mcgraw-Hill Interamericana.

Hear, N., Bakewell, O. and Long, K., 2012, Drivers of Migration. Migrating Out of Poverty. Working Paper, pp.1-44, disponible en migratingoutofpoverty.dfid. gov.uk/documents/wp1-drivers-of-migration.pdf

ICE, s/f, Official Website of the Department of Homeland Security, disponible en https://www.ice.gov/

Jáuregui Díaz, José Alfredo y Recaño Valverde, Joaquín, 2014, Una aproximación a las definiciones, tipologías y marcos teóricos de la migración de retorno, disponible en http://www.ub.edu/geocrit/b3w-1084.htm

Lacuesta, Aitor y Puente, Sergio, 2010, El efecto del ciclo económico en las entradas y salidas de inmigrantes en España, disponible en http://www.bde.es/f/ webbde/SES/Secciones/Publicaciones/PublicacionesSeriadas/DocumentosTrabajo/10/Fic/dt1016.pdf 
Manzur Guzmán, Ángel, 2009, Análisis gráfico. Parte I. Escalas lineales y logaritmicas, disponible en http://www.izt.uam.mx/newpage/contactos/anterior/ n75ne/analisis-grafico1.pdf

Márquez Covarrubias, Humberto, 2010, “Desarrollo y migración: una lectura desde la economía política crítica”, en Migración y Desarrollo, núm. 14, pp. 59-87, Red Internacional de Migración y Desarrollo, Zacatecas, México.

Massey, Douglas S. y Pren, Karen A., 2012, "Origins of the New Latino Underclass", en Race and Social Problems, 4, 5-17.

Massey, Douglas and Pren, Karen A., 2016, La guerra de los Estados Unidos contra la inmigración. Efectos paradójicos, disponible en https://www.ncbi.nlm.nih. gov/pmc/articles/PMC4827256/

Massey, Douglas S, Durand, Jorge y Malone, Nolan J., 2009, Detrás de la trama. Políticas migratorias entre México y Estados Unidos, México, Universidad Autónoma de Zacatecas/Miguel Ángel Porrúa.

Massey, Douglas S., Pren, Karen A. y Durand, Jorge, 2009, "Nuevos escenarios de la migración México-Estados Unidos. Las consecuencias de la guerra antiinmigrante", en Papeles de población, vol. 15 núm. 61, Toluca jul./sep. Disponible en http://www.scielo.org. $\mathrm{mx} /$ scielo.php?script=sci_arttext\&pid $=\mathrm{S} 1405-74252009000300006$

Méndez, Silvestre, 2016, Problemas económicos de México, Mc Graw Hill, México.

Orgaz, Cristina J., 2016, Un estudio demuestra que la economía de Estados Unidos va mejor cuando el presidente es un demócrata, disponible en http://www. fundssociety.com/es/noticias/mercados/un-estudio-demuestra-que-la-economiade-estados-unidos-va-mejor-cuando-el

Rodríguez, Mariángela, 2005, Tradición identidad, mito y metáfora: mexicanos y chicanos en California, disponible en https://books.google.com.mx/books

Salas, Emmanuel Gerardo, Loría Díaz de Guzmán, Eduardo Gilberto y Díaz, Eliseo, 2016, The paradox of Mexican migration to the US 2007-2012, disponible en http://www.scielo.org.mx/scielo.php?script=sci_arttext\&pid $=\mathrm{S} 1405-74252016000100183$

Soysal, Levent, s/f, Un recuento de la migración turca en y hacia Europa: pasado, presente y futuros, disponible en http://rimd.reduaz.mx

Terry, Donald, F. y Wilson, Steven R., 2005, Remesas de inmigrantes: moneda de cambio económico y social, disponible en https://books.google.com.mx/ books?id=iLtWHs8lhKQC\&pg=PA175\&lpg=PA175\&dq=relaci\%C3\%B3n+ent re + deportaciones $+y+$ remesas, + massey \&source $=$ bl\&ots $=$ OA8er63Sf-\&sig $=-7 x$ xxAvz7BnWqsVbL4sn3rzUPQ\&hl=es-419\&sa=X\&ved=0ahUKEwi6oeu6rdzSA $\mathrm{hWrqFQKHcD} 2 \mathrm{D14Q6AEIIjAB} \# \mathrm{v}=$ onepage $\& \mathrm{q}=$ relaci $\% \mathrm{C} 3 \% \mathrm{~B} 3 \mathrm{n} \% 20$ entre $\% 20$ deportaciones $\% 20 \mathrm{y} \% 20$ remesas $\% 2 \mathrm{C} \% 20$ massey\&f=false

Tuirán, Rodolfo y Ávila, José Luís, 2010, “La migración México Estados Unidos 1940-2010”, en Alba, Francisco, Castillo, Manuel Ángel, Verduzco, Gustavo, Los 
grandes problemas de México. Migraciones internacionales. T-III, disponible en https://books.google.com.mx

Verea, Mónica, 2003, Migración temporal en América del Norte: propuestas y respuestas, disponible en https://books.google.com.mx

\section{RESUMEN CURRICULAR DE LOS AUTORES}

\section{Rodolfo Cruz Piñeiro}

Doctorado en Sociología con especialidad en población, por la Universidad de Texas en Austin; maestría en Demografía por El Colegio de México; licenciatura en Economía de la Universidad Veracruzana; miembro del Sistema Nacional de Investigadores desde 1992. Actualmente es profesorinvestigador del Departamento de Estudios de Población. Su principal área de estudio es población y desarrollo de las ciudades que se ubican en la frontera de México y Estados Unidos. Cuenta con la publicación de un libro, tres coordinaciones de libros y más de 40 capítulos y artículos en revistas especializadas. Ha participado en un amplio número de proyectos de investigación. La mayor parte de sus estudios y publicaciones centran su atención en el fenómeno de la migración interna e internacional y en la fuerza de trabajo mexicana. Los trabajos se realizan desde un enfoque sociológico y económico.

Dirección electrónica: rcp1704@hotmail.com

\section{Juan Gabino González-Becerril}

Maestro en Estudios de Población por El Colegio de la Frontera Norte. Es profesor-investigador de tiempo completo en el Centro de Investigación y Estudios Avanzados de la Población de la Universidad Autónoma del Estado de México (CIEAP/UAEM) y es director de la revista Papeles de Población. Entre sus publicaciones recientes destacan Migración mexiquense a Estados Unidos: un análisis interdisciplinario, 2012; Encuesta sobre Migración de Mexiquenses a Estados Unidos (EMMEU 2009), 2012, Demografía indígena en el Estado de México, 2013 (coautor); Migración Internacional: voces del sur 2017 (compilador); todas las publicaciones bajo el sello editorial de CIEAP-UAEM.

Dirección electrónica: gonzalezg2012@hotmail.com

Artículo recibido el 29 de mayo de 2017 y aprobado el 27 de septiembre de 2018 . 